\title{
Mesospheric temperature soundings with the new, daylight-capable IAP RMR lidar
}

\author{
Michael Gerding, Maren Kopp, Josef Höffner, Kathrin Baumgarten, and Franz-Josef Lübken \\ Leibniz Institute of Atmospheric Physics at the Rostock University, Kühlungsborn, Germany \\ Correspondence to: Michael Gerding (gerding@iap-kborn.de)
}

Received: 20 April 2016 - Published in Atmos. Meas. Tech. Discuss.: 3 May 2016

Revised: 15 July 2016 - Accepted: 19 July 2016 - Published: 11 August 2016

\begin{abstract}
Temperature measurements by lidar are an important tool for the understanding of the mean state of the atmosphere as well as the propagation of gravity waves and thermal tides. Though, mesospheric lidar soundings are often limited to nighttime conditions (e.g., solar zenith angle $>96^{\circ}$ ) due to the low signal-to-noise ratio during the day. By this, examination of long-period gravity waves and tides is inhibited, as well as soundings in summer at polar latitudes. We developed a new daylight-capable RayleighMie-Raman (RMR) lidar at our site in Kühlungsborn, Germany $\left(54^{\circ} \mathrm{N}, 12^{\circ} \mathrm{E}\right)$, that is in routine operation since 2010 for temperature soundings up to $90 \mathrm{~km}$ or $\sim 75 \mathrm{~km}$ (night or day) and soundings of noctilucent clouds. Here we describe the setup of the system with special emphasis on the daylight suppression methods like spatial and spectral filtering. The small bandwidth of the Fabry-Pérot etalons for spectral filtering of the received signal induces an altitude-dependent transmission of the detector. As a result, the signal is no longer proportional to the air density and the hydrostatic integration of the profile results in systematic temperature errors of up to $4 \mathrm{~K}$. We demonstrate a correction method and the validity of correction by comparison with data obtained by our co-located, nighttime-only RMR lidar where no etalon is installed. As a further example a time series of temperature profiles between 20 and $80 \mathrm{~km}$ is presented for day and night of 9-10 March 2014. Together with the other data of March 2014 these profiles are used to calculate tidal amplitudes. It is found that tidal amplitudes vary between $\sim 1$ and $5 \mathrm{~K}$ depending on altitude.
\end{abstract}

\section{Introduction}

Temperature is one of the key parameters for the understanding of the atmosphere. The mean state is mainly a result of the residual circulation and the radiative budget, as well as the chemical and turbulent heating and cooling. Superposed spatiotemporal temperature variations resulting from planetary, tidal and gravity waves are observed. Propagating waves become increasingly important in the middle atmosphere because of decreasing air density. Observational capabilities have improved in the last decade due to sophisticated satellite-borne instruments like TIMED/SABER, but several constraints remain, such as a coarse spatiotemporal resolution. While lacking global coverage, ground-based lidars are the only technique for observation of temporal temperature variations on scales of 10-60 min in the middle atmosphere (e.g., Meriwether and Gerrard, 2004). However, lidars suffer from solar photon flux during the day, and therefore most lidar observations are limited to nighttime conditions. This hinders, e.g., measurements at polar latitudes in summer and the observation of tidal temperature variations, and it may also bias the retrieval of the seasonal temperature variation due to unresolved tides (Chen et al., 2000). However, a potential bias might affect all data sets with limited temporal coverage such as sun-synchronous orbiting satellites.

A few daylight-capable systems have been developed specially for resonance lidars, often using atomic vapor cells (e.g., Chen et al., 1996; Fricke-Begemann et al., 2002; Friedman et al., 2012) or Fabry-Pérot etalons (FPEs; e.g., Chu et al., 2002) for spectral filtering of the received signal. These lidars are typically limited to the $85-105 \mathrm{~km}$ altitude range. Below, Rayleigh backscatter is used for temperature retrieval. Several systems cover the whole range up to $\sim 85 \mathrm{~km}$ at night, but for daylight operation the range is typically lim- 
ited to $\sim 60 \mathrm{~km}$ (e.g., von Zahn et al., 2000; Klekociuk et al., 2003; Blum and Fricke, 2005) if available at all. While all these daylight-capable lidars are installed at polar latitudes, there is a general lack of temperature data during day from mid-latitudes, especially for the mesospheric altitudes above $60 \mathrm{~km}$.

We developed a daylight-capable Rayleigh-Mie-Raman (RMR) lidar at Leibniz-Institute of Atmospheric Physics (IAP) in Kühlungsborn, Germany $\left(54^{\circ} \mathrm{N}, 12^{\circ} \mathrm{E}\right)$, in 2009/2010. The new system has already proven to observe noctilucent clouds (NLCs; also known as polar mesospheric clouds) during day and night (Gerding et al., 2013b) as well as tidal temperature variations (Kopp et al., 2015). Soundings have been performed at solar elevations of up to $59^{\circ}$, i.e., the maximum elevation during summer. The new lidar is co-located with a nighttime-only RMR lidar that has been in operation since 1997, e.g., for observation of temperatures (Alpers et al., 2004; Gerding et al., 2008; Rauthe et al., 2008) and NLCs (Alpers et al., 2000; Gerding et al., 2013a).

Here we describe the instrumental setup of the new RMR lidar at Kühlungsborn (Sect. 2). We focus on the special requirements for daytime operation. Narrowband spectral filtering entails a somewhat different temperature retrieval, as the backscatter signal is no longer proportional to the air density (see Sect. 3). We describe the temperature retrieval for the new lidar and compare the results exemplarily with data simultaneously obtained with the old RMR lidar. In Sect. 4 we present an example for temperature lidar soundings covering day and night. We also show tidal temperature variations for this period, affirming the results of Kopp et al. (2015). In some examples the data of the RMR lidar are complemented by observations with the co-located potassium resonance lidar (von Zahn and Höffner, 1996). The potassium lidar allows daytime soundings since year 2000 (e.g., Fricke-Begemann and Höffner, 2005).

\section{Instrumental setup of the new IAP RMR lidar}

We installed a new RMR lidar at Kühlungsborn in 2009/2010 and started regular operation in summer 2010. The design requirements for the RMR lidar are as follows:

- reduction of background count rate by more than 4 orders of magnitude with a combination of spatial filtering (narrow field of view) and spectral filtering (narrowband detector);

- co-axial transmitter and receiver for complete overlap in the stratosphere and mesosphere;

- high dynamic range of the detector system for signal coverage between $\sim 20$ and $90 \mathrm{~km}$;

- detection of elastic $(532 \mathrm{~nm})$ and inelastic $\left(\mathrm{N}_{2}\right.$-Raman shifted, $608 \mathrm{~nm}$ ) backscatter for future aerosol correction in the lower stratosphere;

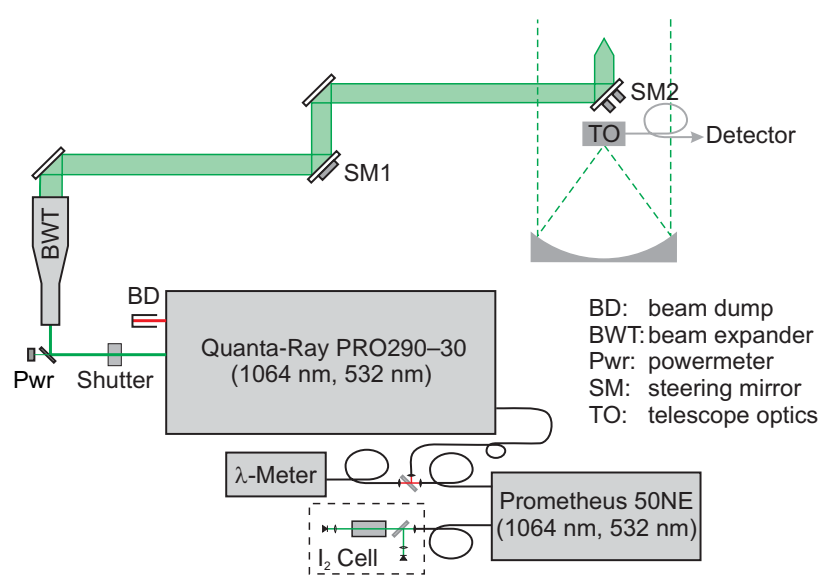

Figure 1. Setup of the transmitter of the new RMR lidar. Only the most important fiber cables of the seed laser are shown; additional fibers are available, e.g., for adjustment of the detector. SM1 is Piezo-mounted for fast beam stabilization, and SM2 is motorized for coarse adjustment of the beam axis.

- widely automated system (e.g., active beam stabilization), allowing regular observations even with briefly trained staff;

- operation at broken clouds.

The new lidar is optimized for soundings of middle atmospheric temperatures and NLCs during both day and night. Details of the instrumental setup are shown in Figs. 1 and 2.

The flashlamp-pumped power laser Newport Spectra Physics Quanta-Ray PRO 290-30 is seeded by the continuous wave laser Innolight Prometheus 50NE (Fig. 1). The external seed laser allows a better wavelength control and wavelength monitoring compared to an internal seed laser. For this, it is locked to an iodine line by means of absorption spectroscopy using the frequency-doubled output of the seed laser. Until June 2015 the iodine line $1111\left(\lambda_{\text {vac }}=532.241 \mathrm{~nm}\right)$ was used. Since then we use line 1109 at $\lambda_{\text {vac }}=532.255 \mathrm{~nm}$, corresponding to a seeding wavelength $\lambda_{\text {seed,vac }}=1064.51 \mathrm{~nm}$ or $\lambda_{\text {seed,air }}=1064.22 \mathrm{~nm}$ for vacuum and air respectively. The new seeding wavelength results in the advantage of a second harmonic "in air" $\left(\lambda_{\text {air }}=532.11 \mathrm{~nm}\right)$ being identical with a Fraunhofer line in the solar spectrum, i.e., a $\sim 25 \%$ reduced solar background. The emission wavelength of the seed laser is monitored by a High Finesse WSU wavelength meter, while the fine control of the emission wavelength is done by means of the above mentioned iodine absorption spectroscopy. Additional fiber ports of the seeding system are used for adjustment of the optical bench, for seeder power monitoring, etc. Due to the low signal-to-noise ratio (SNR) we actually only use the second harmonic at $532 \mathrm{~nm}$ and not the fundamental laser output at $1064 \mathrm{~nm}$. The frequencydoubled output of the power laser is guided through a $10 \times$ beam widening telescope (BWT) for reduction of the beam divergence from $<0.5$ to $0.05 \mathrm{mrad}$. Two steering mirrors 


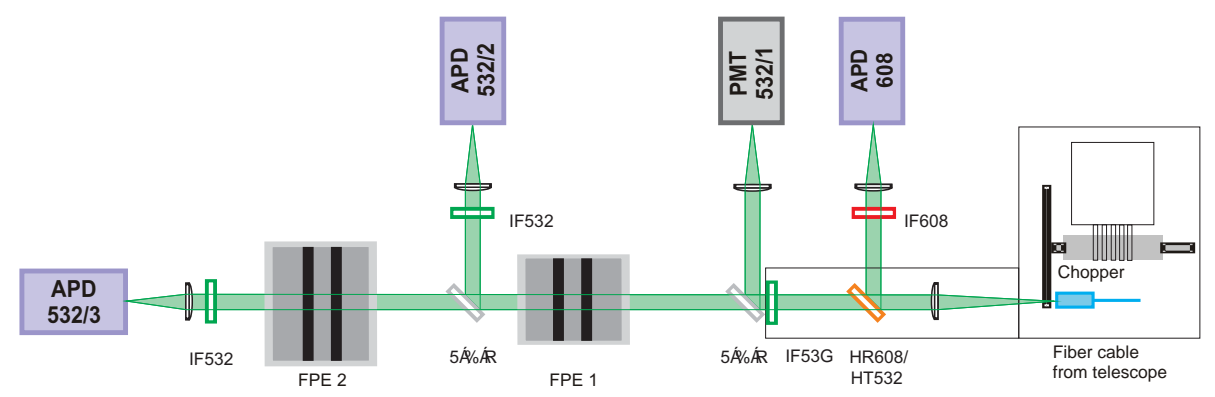

Figure 2. Setup of the receiver of the new RMR lidar. Photons collected by the telescope are guided to the receiver by a multi-mode fiber shown at the right side of the figure.

and one fixed mirror are used to guide the light into the atmosphere, co-axially with the receiving telescope. The first of these steering mirrors is Piezo-mounted and used for beam stabilization (Eixmann et al., 2015). By computer-controlled beam stabilization the beam axis is fixed to the optical axis of the telescope on a single pulse basis to overcome the effects of, e.g., atmospheric turbulence on the geometrical overlap of beam and telescope. The remaining jitter is $\sim 3-5 \mu \mathrm{rad}$. The second steering mirror is used for coarse adjustment of the beam axis, e.g., if the range of the Piezo mirror is too small due to slow but large thermal drifts. The coarse steering needs to be done only a few times per $24 \mathrm{~h}$.

The backscattered light is collected by a $32 \mathrm{in} .(\sim 81 \mathrm{~cm})$ parabolic $f / 4$ mirror (cf. Table 1 ). The telescope mount is made from carbon-fiber reinforced plastic, ensuring minimal thermal expansion. As described by Eixmann et al. (2015), $90 \%$ of the received photons are guided to a fiber cable for lidar detection and $10 \%$ are used for beam stabilization. The fiber cable has a core diameter of only $0.2 \mathrm{~mm}$, resulting in a field of view (FOV) of only $62 \mu \mathrm{rad}$. The small FOV has two major advantages: (i) the number of photons received from scattered sunlight is much smaller compared to larger FOVs, e.g., a factor of $\sim 100$ smaller compared to our nighttimeonly RMR lidar; (ii) the low core diameter of the fiber with numerical aperture NA $=0.11$ enables to build up a highly efficient detector with small divergence at small $(\sim 22 \mathrm{~mm})$ beamwidth, see below. The narrow FOV requires an active beam stabilization because otherwise thermal drifts and atmospheric turbulence would tilt the laser beam out of the FOV within a few seconds. The optical setup of the receiver system is shown in Fig. 2. A chopper is used to prevent the detectors from the large number of photons scattered in the lower atmosphere. First, $N_{2}$-Raman shifted photons at $608 \mathrm{~nm}$ are guided to an avalanche photodiode (APD). This detector is only operational during the night due to insufficient SNR during the day. A narrowband interference filter (IF; FWHM $=130 \mathrm{pm}$ ) at $532 \mathrm{~nm}$ blocks a large part of the received sunlight. The whole setup up to the IF is shielded by hardboard to prevent multi-scatter and light leakage that may allow undesired photons hitting the detectors. Three different detectors are used for the elastic backscatter signal at
Table 1. Technical parameters of the IAP RMR lidar.

\begin{tabular}{ll}
\hline Instrument parameter & Value \\
\hline Wavelength (air) until June 2015, nm & 532.096 \\
Wavelength (vac.) until June 2015, nm & 532.241 \\
Wavelength (air) since June 2015, nm & 532.110 \\
Wavelength (vac.) since June 2015, nm & 532.255 \\
Repetition rate, pps & 30 \\
Laser power @ 532 nm, W & $\sim 20$ \\
Beam diameter after expansion, mm & 90 \\
Beam divergence after expansion, $\mu \mathrm{rad}$ & 50 \\
Telescope diameter, m & 0.81 \\
Telescope focal length, m & 3.25 \\
Telescope field of view, $\mu \mathrm{rad}$ & 62 \\
Interference filter width (FWHM), pm & 130 \\
Etalon 1 free spectral range, pm & 120 \\
Etalon 1 observed finesse & 27 \\
Etalon 2 free spectral range, pm & 140 \\
Etalon 2 observed finesse* & 20 \\
\hline
\end{tabular}

* As used in detector; larger finesse for ideal illumination.

$532 \mathrm{~nm}$. The combination of these allows us to monitor the transmission of the etalons. Additionally, the lower sensitivity of detector $532 / 1$ in combination with the $5 \%$ beam splitter allows us to measure in the lower stratosphere where the detector 532/3 would be saturated.

Further reduction of the solar scatter is achieved by a double FPE, with technical details described in Table 1. In order to keep the setup simple and reliable, we use fixed-spacer etalons in a pressurized housing instead of Piezo-controlled etalons. The transmission of the particular etalons is $\sim 92 \%$ (with optimally collimated light). Tuning of the etalons is done by changing the pressure inside the stainless steel housing, using either backscattered light from the atmosphere or light of the seed laser. Depending on leakage rate this is done every $2-6$ weeks. The maximal mismatch of laser line and etalon center wavelength by this method can be estimated with $\sim 0.2 \mathrm{pm}$. Photon counts are recorded by transient recorders (manufactured by Licel, Germany) and accumulated over 1000 laser pulses $(\sim 30 \mathrm{~s})$. In an optional 


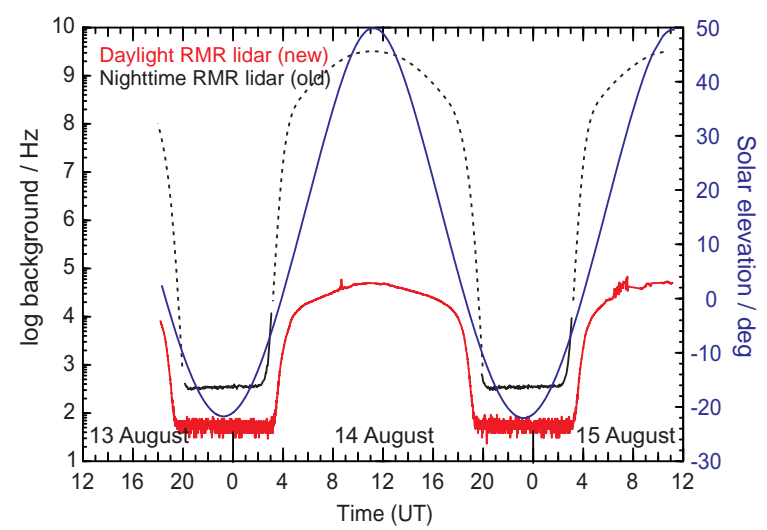

Figure 3. Temporal variation of the background count rate for the new RMR lidar under summer conditions (red). The nighttime lidar was additionally operated during darkness (black line), and the background is extrapolated for daylight conditions (black dashed line). Solar elevation is shown for comparison (blue line).

"cloud mode" the data are pre-integrated over 50 laser pulses and only used for final integration if the SNR is sufficiently large. By this we can also operate during the gaps between fast traveling clouds that would otherwise be too short to be usable. Note that the strongly increased background even from only a few seconds of "cloudy" data would contaminate the whole integrated profile. The vertical resolution of the profiles is $15 \mathrm{~m}$. The signals are recorded up to $245 \mathrm{~km}$ altitude, with the range gates above $\sim 117 \mathrm{~km}$ being used for background calculation.

Overall, the background count rate from solar backscatter is reduced by more than 4 orders of magnitude compared to our nighttime RMR lidar. Figure 3 shows the diurnal change of the background count rates for the new, daylight-capable RMR lidar. The background count rate of the nighttime lidar is extrapolated from twilight conditions and the data of the new lidar, taking the different efforts of spectral and spatial filtering into account. The solar elevation is shown for comparison. The background count rate of the new lidar starts rising shortly before sunrise. It increases by $\sim 2$ orders of magnitude within about $1 \mathrm{~h}$ until the sun is a few degree above the horizon. Later, the background increases slower until its maximum near solar culmination. For comparison, the background count rate of our old RMR lidar, representing a standard RMR lidar, increases already $1 \mathrm{~h}$ earlier at solar elevation of $\sim-8^{\circ}$. Typically, this lidar is switched of near $10 \mathrm{kHz}$ background count rate due to insufficient SNR. During nighttime, background count rate is still higher than with the new lidar due to higher dark count rate of the detector. Examples of raw data profiles are shown in Fig. 4 for $1 \mathrm{~h}$ integration time. A period near highest solar elevation (10:0011:00 UT) is compared with nighttime conditions (22:0023:00 UT). Data in the most sensitive channel 532/3 reach the noise level in $\sim 85 \mathrm{~km}$ during day and $\sim 100 \mathrm{~km}$ during the night. Compared to that, the signal of channel 532/2 is
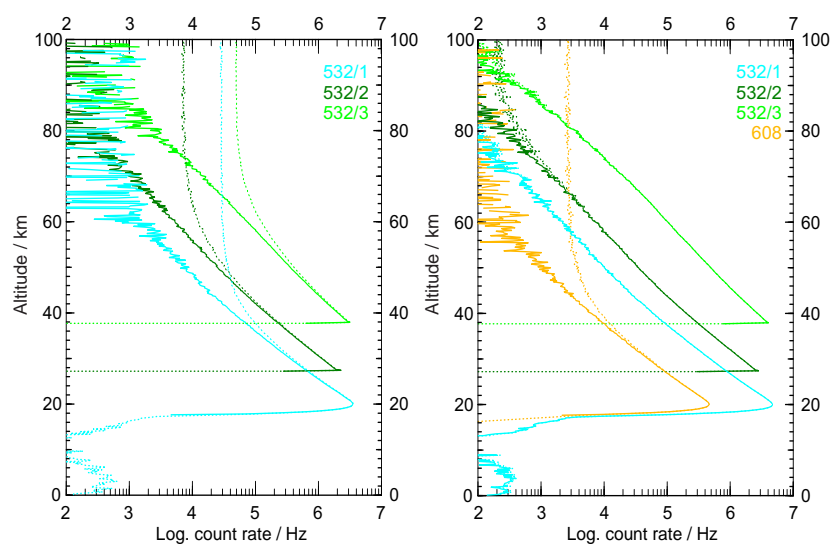

Figure 4. Raw data profiles before (dotted line) and after (solid line) background subtraction, averaged for $1 \mathrm{~h}$ of between 10:00 and 11:00 UT (left) and 22:00-23:00 UT (right) on 14 August 2012.

about 1 order of magnitude weaker. The difference between $532 / 2$ and 532/1 is mainly due to the different detectors (cf. Fig. 2). During the night the vibrational-Raman backscatter at $608 \mathrm{~nm}$ is recorded, additionally. The signal strength is nearly $1 / 1000$ of the Rayleigh signal due to the weaker backscatter cross section for Raman backscatter.

As demonstrated in the next sections, effective background suppression with our new RMR lidar allows us to observe mesospheric temperatures up to $\sim 75 \mathrm{~km}$ during the day ( $\sim 90 \mathrm{~km}$ during the night). Actually, temperature calculations are limited to altitudes above $30 \mathrm{~km}$. In the near future, the $608 \mathrm{~nm}$ channel will be used for aerosol correction below $\sim 30 \mathrm{~km}$ (cf. Gerding et al., 2008). Furthermore, the rotational Raman channel of the old, nighttime RMR lidar, being equipped with a separate $50 \mathrm{~cm}$ telescope, will be used with the new lidar during the night. The new RMR lidar is operated semiautomatically and can be controlled by briefly trained staff. Depending on weather conditions more than $1000 \mathrm{~h}$ of data are obtained per year.

\section{Temperature retrieval with transmission correction}

Temperatures are calculated using the well-known Rayleigh integration method as described by Hauchecorne et al. (1991). This method relies on the fact that the observed backscatter profile is proportional to the air density profile. Unfortunately, for our new RMR lidar, because of the narrowband daylight filter, this is only true after the correction described below. The bandwidth (FWHM) of the first etalon is $\sim 4.4 \mathrm{pm}$, as calculated from finesse and free spectral range given in Table 1. This is in the range of the Doppler broadening of the backscattered radiation $(\sim 2.5 \mathrm{pm}$, depending on temperature). Due to the Airy function-shaped transmission function, part of the backscattered photons are already blocked. Figure 5 (left) shows the spectral shapes of the transmission function of the first etalon and the Doppler 

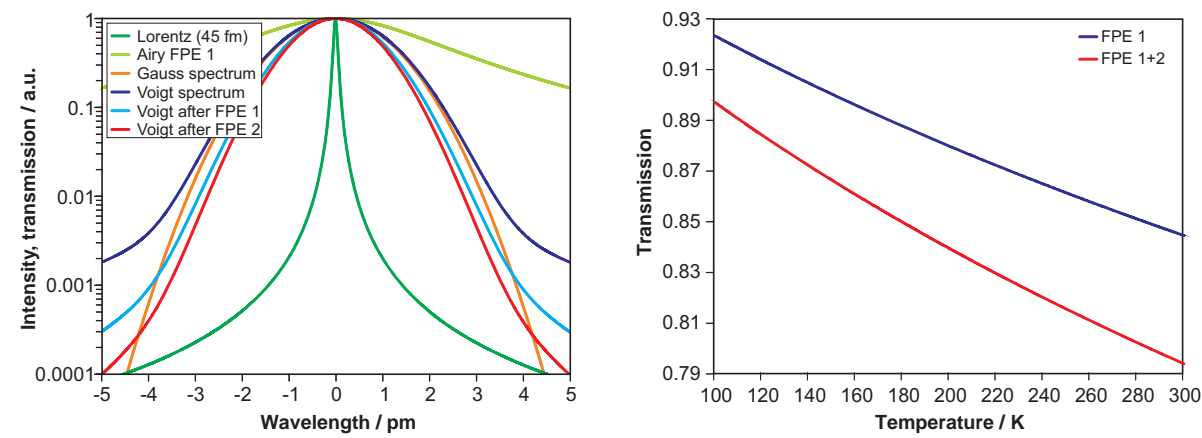

Figure 5. Left: Lorentz spectrum of the pulse laser (green), Airy transmission function of etalon 1 (light green, maximum set to $100 \%$ ) and Voigt shaped, Doppler broadened Rayleigh backscatter spectrum (for $300 \mathrm{~K}$ ) before the etalons (blue), behind the first (light blue) and second etalon (red). A Gaussian spectrum for $300 \mathrm{~K}$ is shown for comparison (orange). Right: transmission of the first (blue) and both etalons (red) depending on atmospheric temperature, i.e., Doppler broadening. Numbers given with respect to an etalon with $100 \%$ transmission.

broadened backscatter before and after the first etalon and after the second etalon on a logarithmic scale. The bandwidth of the pulse laser has to be taken into account. While we do not have a possibility for direct measurement of the pulse width, we can estimate a Lorentz shaped spectrum with $\sim 45 \mathrm{fm}$ FWHM from the laser pulse length of $\sim 10 \mathrm{~ns}$ (Heisenberg limit). In fact, we have also calculated the effect of larger bandwidths and found that the additional correction for, e.g., $85 \mathrm{fm}$ FWHM is much below $0.1 \mathrm{~K}$. The convolution of the Lorentz shaped laser spectrum with the Gaussian function resulting from the Doppler effect is a Voigt function. In Fig. 5 we show the Doppler broadened backscatter spectrum for $300 \mathrm{~K}$ temperature and compare with the pure Gaussian that can be expected if the laser bandwidth can be neglected. Additionally we show the spectra after the light passes the first and the second etalon. Obviously, the shape of the transmitted spectrum has changed and hence the number of transmitted photons is reduced compared to the incident light. Please note that the effect of the etalon on the transmitted light is largest at high temperatures like in Fig. 5. The effect of the laser bandwidth on the Voigt function is larger at low temperatures, when the Doppler effect gets smaller; i.e., the relative effect of the Lorentz function gets larger.

For an isothermal atmosphere the transmission of the etalons would be constant and the observed backscatter profile would still be proportional to the air density. For a real, non-isothermal atmosphere the proportionality between signal and air density is no longer valid. The transmission of the double etalon depends on the atmospheric temperature at the altitude of scattering: for atmospheric temperatures of 160 and $300 \mathrm{~K}$ the transmission compared to the transmission of unbroadened backscatter is reduced to 86 and $79 \%$, respectively (Fig. 5, right), and the backscatter profile will be distorted.

In order to calculate temperatures by the Rayleigh integration method the backscatter profile needs to be corrected for the changing etalon transmission. This is done in our retrieval by an iterative method. First, an approximate temper-

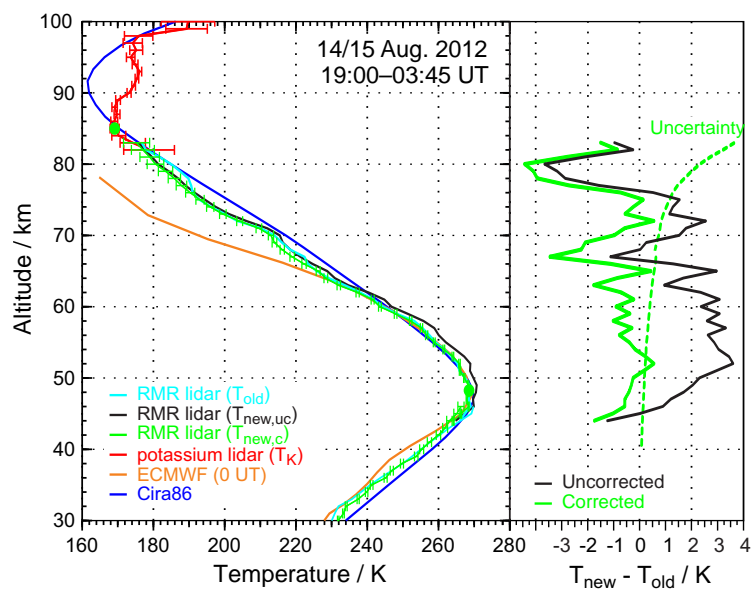

Figure 6. Nightly mean temperature profiles for 14/15 August 2012 Left: data from the potassium lidar $\left(T_{\mathrm{K}}\right.$, red) are used for initialization of the hydrostatic temperature retrieval of the RMR lidars. Data of the old, nighttime RMR lidar $T_{\mathrm{old}}$ are shown in light blue; that of the new RMR lidar are in black $\left(T_{\text {new,uc }}\right)$ and green $\left(T_{\text {new,c }}\right)$. Data from CIRA-86 (blue) and ECMWF (orange) are shown for comparison. Right: differences between data of the old and new RMR lidar, before (black) and after (green) correction. The statistical uncertainty for the new RMR lidar is similar to the numbers for the old lidar and shown as dashed line.

ature is calculated ignoring the changing transmission and assuming the backscatter profile to be proportional to density. This approximated temperature profile is then used to calculate a corrected backscatter profile, dividing the count rate at each altitude bin by the transmission of the etalons for the temperature-broadened signal at this particular altitude. If done repetitively, for typical conditions the correction in the second iteration is already much smaller than the statistical uncertainty (not shown). Therefore we use only one iteration. Figure 6 shows an example for a temperature profile before and after the transmission correction $\left(T_{\text {new,uc }}\right.$ and $T_{\text {new,c }}$ respectively). Data are obtained during darkness, 
allowing comparison with the simultaneous, co-located profile measured by the nighttime RMR lidar ( $\left.T_{\text {old }}\right)$. The hydrostatic integration is initialized at $85 \mathrm{~km}$ by the temperature observed simultaneously by our co-located potassium lidar $\left(T_{\mathrm{K}}\right)$. During top-down hydrostatic integration in the mesosphere, the uncorrected temperature data $T_{\text {new,uc }}$ of the new RMR lidar increase generally slightly stronger than $T_{\text {old }}$. Just above the stratopause differences get smaller again. ECMWF data cannot be used for comparison at the model's sponge layer above $65 \mathrm{~km}$, where the differences to both lidar data sets ( $\left.T_{\text {old }}, T_{\text {new,uc }}\right)$ are up to $20 \mathrm{~K}$. However, below that altitude the data confirm the observation of the old RMR lidar, indicating that $T_{\text {new,uc }}$ is wrong. Also the corrected temperature profile $T_{\text {new,c }}$ is shown in Fig. 6. Within the statistical uncertainty it closely agrees with $T_{\text {old }}$. The lower Rayleigh channels of both RMR lidars are used below $\sim 48 \mathrm{~km}$. They also agree within the statistical uncertainty. A correction may not be applied to the data of the new RMR lidar as the receiver before the first etalon is used.

Differences between temperature profiles of the old and new RMR lidar are plotted on the right side of Fig. 6. Near $80 \mathrm{~km}$ the uncorrected new profile shows slightly lower values $\left(T_{\text {new,uc }}-T_{\text {old }}<0\right)$. However, this difference is still within the combined statistical uncertainty. Below, the effect of temperature-dependent etalon transmission starts to dominate. Subsequently, $T_{\text {new,uc }}$ is warm biased by $\sim 3 \mathrm{~K}$ above the stratopause. This bias is not visible with the corrected new profile $\left(T_{\text {new,c }}-T_{\text {old }}\right)$. Here, an additional difference occurs around $67 \mathrm{~km}$. Like the discrepancy below $80 \mathrm{~km}$ this may due to different (signal-dependent) smoothing windows used for both lidars (cf. Alpers et al., 2004; Gerding et al., 2008). Furthermore, the statistical uncertainty $(1 \sigma)$ of the photon count profiles should be taken into account, resulting in a temperature uncertainty of $\sim 2.5 \mathrm{~K}$ for both RMR lidars at $80 \mathrm{~km}$ altitude. The difference between both curves directly shows the amount of temperature correction. The correction is $\sim 0.5 \mathrm{~K}$ at $83 \mathrm{~km}$ and increases with decreasing altitude. Between 55 and $60 \mathrm{~km}$ it reaches a maximum of $\sim 3.5 \mathrm{~K}$. Below that altitude decreases strongly and is only $0.5 \mathrm{~K}$ in the lowest altitude bin of this detection channel. There is an uncertainty in the temperature correction due to possible mismatches of laser line and the center of the etalon transmission function. For typical (maximal) deviations of $0.2 \mathrm{pm}$ this would result in an overcompensation (i.e., underestimation of true temperature) by $\sim 0.4 \mathrm{~K}$. Please note that this potential error has a different sign than the effect of spectral broadening of the laser pulse.

\section{Initial observations during day and night}

The daytime-capable RMR lidar at Kühlungsborn is operated continuously since March 2011 with some additional observations in June/July 2010. Temperature soundings are performed whenever weather conditions allow for at least $3 \mathrm{~h}$ of

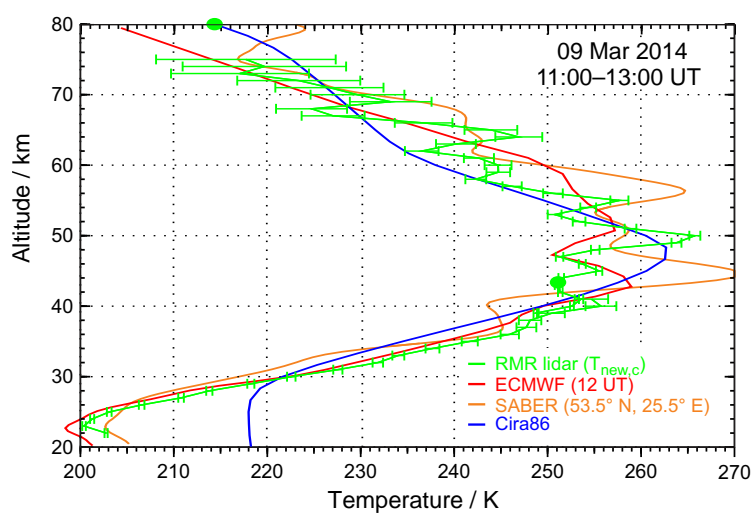

Figure 7. Temperature profile from the new RMR lidar (green, with error bars) during daylight for 9 March 2014 (11:00-13:00 UT). ECMWF data for 12:00 UT (red), a temporally coincident SABER profile (orange; $11: 43 \mathrm{UT}, 53.5^{\circ} \mathrm{N}, 25.5^{\circ} \mathrm{E}$ ) as well as CIRA-86 data (blue) are shown for comparison.

operation, independent of daylight conditions. Until March 2016 we collected about $6200 \mathrm{~h}$ of data. A detailed study of the temperature data set is outside the scope of this paper. Kopp et al. (2015) published a study about the tidal temperature variation at our site (using only the upper $532 \mathrm{~nm}$ channel and temperature variations), while Gerding et al. (2013b) focussed on the diurnal variation of NLCs. Here we present some temperature data of March 2014 as well as the tidal amplitudes of this month to demonstrate the capabilities of the new RMR lidar at Kühlungsborn.

Figure 7 shows the temperature profile observed on 9 March 2014 at 12:00-14:00 UT. Solar elevation was up to $28^{\circ}$. The temperature retrieval was initialized for the higher $532 \mathrm{~nm}$ channel at $80 \mathrm{~km}$ by the CIRA- 86 climatology (Fleming et al., 1990). The data of the high Rayleigh channel are taken at $44 \mathrm{~km}$ altitude to start the integration for the low $532 \mathrm{~nm}$ channel. The signal from below $22 \mathrm{~km}$ altitude is blocked by the chopper, and no measurements are available here. The lowermost data show a temperature minimum at $23 \mathrm{~km}$ with temperatures as low as $200 \mathrm{~K}$. A stratopause is hard to identify in this individual profile, because temperatures vary strongly with altitude between 40 and $70 \mathrm{~km}$. The vertical temperature gradient is down to $-6 \mathrm{~K} \mathrm{~km}^{-1}$ in the lower mesosphere. Above $70 \mathrm{~km}$, temperatures decrease smoothly, but the increasing uncertainty of up to $10 \mathrm{~K}$ should be taken into account. Of course, the large temperature variability can be questioned, as it may be an artifact due to issues of, e.g., geometric overlap, detector saturation or additional aerosol scattering. For a co-axial system like the system described here, complete geometric overlap is limited to the range where the telescope is optimally focussed. The near field of our telescope extends up to the lower stratosphere, but we do not have any indications for de-focussing above $\sim 20 \mathrm{~km}$. Geometric overlap may decrease with altitude if the laser is not properly adjusted to the optical axis of the 


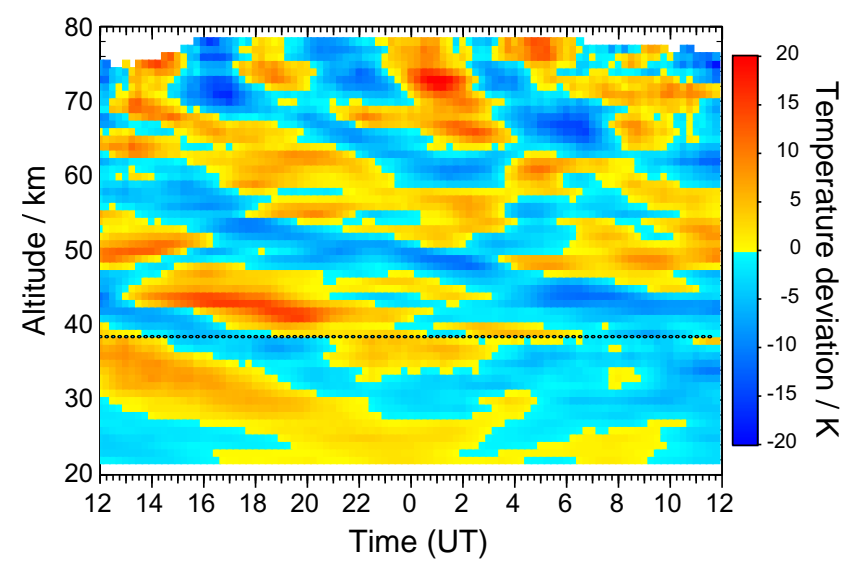

Figure 8. Time series of temperature data for 9-10 March 2014. Only deviations from the mean profile are shown. The black dotted line denotes the transition from the higher to the lower Rayleigh channel. Temperatures are calculated every $15 \mathrm{~min}$ with $2 \mathrm{~h}$ integration.

telescope, but this would result in a cold bias across a wide altitude range and not in oscillations of temperature. Effects of detector saturation should be strongest at altitudes of highest signal, i.e., at $40-45 \mathrm{~km}$, but not in the middle mesosphere where the signal is moderate. Aerosol layers yield to seemingly strongly varying temperatures if ignored in Rayleigh temperature retrieval. However, optically visible aerosol layers have not been reported above $50 \mathrm{~km}$ so far. We have also plotted the ECMWF temperature profile for 12:00 UT. It demonstrates large variability similar to the lidar data, even if the model resolution is not high enough to reproduce our observations in full detail. A SABER temperature profile is available for $11: 43 \mathrm{UT}$ and $53.5^{\circ} \mathrm{N}, 25.5^{\circ} \mathrm{E}$. The data nicely resemble the general temperature structure observed by our lidar. The differences in phase and absolute temperatures are expected because of the large latitudinal separation.

During 9-10 March 2014 soundings continued for about $40 \mathrm{~h}$. Figure 8 shows a subsection of $24 \mathrm{~h}$. Only the deviations of the individual profiles from the $24 \mathrm{~h}$ mean are plotted to highlight the temperature variations. Downward propagating structures of different periods and vertical wavelengths are visible and are presumably due to superposing gravity and tidal waves. Temperature variations depend on altitude and are up to $\pm 15 \mathrm{~K}$. As in Fig. 7 the retrieval for all profiles is initialized at $80 \mathrm{~km}$ by CIRA- 86 data. Because the climatological temperature might deviate from the true temperature, we assume an uncertainty for the seed temperature of $10 \mathrm{~K}$, adding to the uncertainty of photon statistics. We limit our retrieval to $10 \mathrm{~K}$ overall uncertainty, resulting in a uppermost altitude of $78 \mathrm{~km}$ during night and $75 \mathrm{~km}$ during day. If different start altitudes for day and night are acceptable, temperature soundings can be extended during the night up to at least $85-90 \mathrm{~km}$ by choosing higher start altitudes.

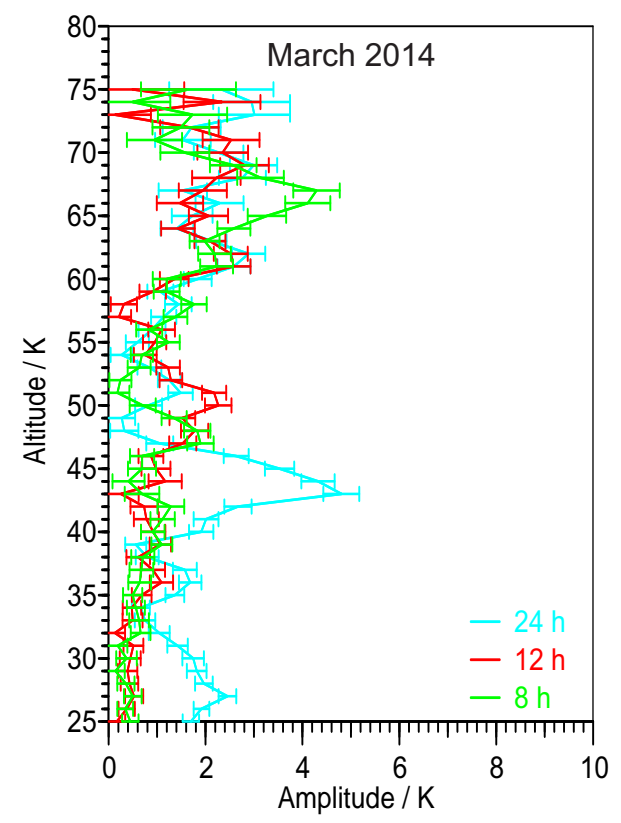

Figure 9. Amplitude profile for diurnal (blue), semidiurnal (red) and terdiurnal (green) tidal components from a composite of all March 2014 data.

A single $24 \mathrm{~h}$ time series does not allow distinguishing between gravity waves and tides and, e.g., estimating tidal amplitudes. As reported by Kopp et al. (2015), about $100 \mathrm{~h}$ of data are necessary to get reliable fits of the diurnal tide and higher harmonics from temperature composites. Overall, in March 2014 we have $125 \mathrm{~h}$ of temperature data available (with $\geq 6 \mathrm{hday}^{-1}$ ). In this month tidal amplitudes strongly vary with altitude (Fig. 9). The diurnal tide maximizes at $\sim 43 \mathrm{~km}$ (amplitude $\sim 5 \mathrm{~K}$ ), gets small close to $50 \mathrm{~km}(<0.5 \mathrm{~K})$ and then generally increases with altitude in the mesosphere. A secondary maximum is found around $28 \mathrm{~km}$. The semidiurnal tide in March 2014 is alternately increasing and decreasing, suggesting several filtering layers in the course of the month for the particular tidal mode. Additionally it cannot be ruled out that some signatures of a strong gravity wave with about $12 \mathrm{~h}$ period are still visible even in the composite of $125 \mathrm{~h}$ of data. Amplitudes are between 0.5 and $3 \mathrm{~K}$. The altitudinal structure of the terdiurnal tide is similar but with a maximum at $\sim 67 \mathrm{~km}$. In general, at altitudes above $50 \mathrm{~km}$ the higher harmonics often dominate against the diurnal tide or are at least similar. However, the maximum of the diurnal tide near $45 \mathrm{~km}$ confirms our previous observations. Below the stratopause the amplitudes in March are often around $5 \mathrm{~K}$ and, by this, much larger than during the rest of the year. Above $50 \mathrm{~km}$ we observe some variation in the March tidal amplitudes. Compared to the data published by Kopp et al. (2015), the terdiurnal tide was much stronger in 2014, while the semidiurnal tide was of similar strength. The comparison of the data presented here with previous publications demonstrates the necessity of continuous temperature 
soundings in the middle atmosphere. Our temperature soundings during day and night allow for the retrieval of tides and their interannual, seasonal and - if weather allows - shortterm variability.

\section{Conclusions}

We have demonstrated first temperature soundings by RMR lidar during full daylight (solar elevation much larger than $40^{\circ}$ ) in the middle atmosphere up to $\sim 75 \mathrm{~km}$. Observations during daylight conditions request a special design of the lidar receiver that effectively suppresses the background count rate from solar photons but has a high transmission at the laser wavelength. We have described our setup with a narrow telescope FOV ( $60 \mu \mathrm{rad}$ instead of $600-1000 \mu \mathrm{rad}$ of a standard RMR lidar) equipped with active beam stabilization. In addition to this spatial filtering we applied a narrowband IF and double FPEs with 4.4 and $7.0 \mathrm{pm}$ bandwidth (FWHM) for spectral filtering. Overall the solar background is reduced by more than 4 orders of magnitude compared to a typical nighttime RMR lidar. A seed laser is frequency-locked to an iodine absorption line and assures a constant laser emission at the wavelength of the lidar detector. Making use of a Fraunhofer line in the solar spectrum the background is further reduced by $25 \%$ without any signal loss. The narrow FOV allows for a high transmission of the FPE of 92\% at the laser wavelength. The narrowband FPE partly block the Doppler broadened Rayleigh backscatter, affecting the proportionality of the signal to the atmospheric density. Therefore the classical Rayleigh temperature retrieval can not be applied. We have described a data correction scheme that is used to overcome this issue. The validity of our retrieval is demonstrated by comparison with our old, nighttime RMR lidar and ECMWF operational data. The lidar system design is optimized for easy operation, allowing for more than $6200 \mathrm{~h}$ of data since summer 2010. Some examples for temperature soundings in the middle atmosphere during full daylight are presented. The capability for, e.g., observation of tides is demonstrated, showing a dominating diurnal tide in the upper stratosphere in March. In summary, we have presented our approach of building an effective lidar for temperature soundings in an altitude region, where daylight soundings are sparse and, e.g., resonance lidars can not operate.

\section{Data availability}

Lidar data used for this paper are available via IAP's ftp server at ftp://ftp.iap-kborn.de/data-in-publications/ GerdingAMT2016. SABER data have been retrieved from http://saber.gats-inc.com/.
Acknowledgements. We thank our IAP colleagues Torsten Köpnick, Jens Fiedler, Jens Söder and Hägar Holste for their particular contributions to the new RMR lidar at Kühlungsborn. Michael Priester has been helpful in lidar operation and maintenance. This work has partly been supported by the Deutsche Forschungsgemeinschaft (DFG) under grant GE1625/2-1.

Edited by: M. Rapp

Reviewed by: two anonymous referees

\section{References}

Alpers, M., Gerding, M., Höffner, J., and von Zahn, U.: NLC particle properties from a five-color lidar observation at $54^{\circ} \mathrm{N}, \mathrm{J}$. Geophys. Res., 105, 12235-12240, 2000.

Alpers, M., Eixmann, R., Fricke-Begemann, C., Gerding, M., and Höffner, J.: Temperature lidar measurements from 1 to $105 \mathrm{~km}$ altitude using resonance, Rayleigh, and Rotational Raman scattering, Atmos. Chem. Phys., 4, 793-800, doi:10.5194/acp-4-7932004, 2004.

Blum, U. and Fricke, K. H.: The Bonn University lidar at the Esrange: technical description and capabilities for atmospheric research, Ann. Geophys., 23, 1645-1658, doi:10.5194/angeo-231645-2005, 2005.

Chen, H., White, M., Krueger, D. A., and She, C.: Daytime mesopause temperature measurements with a sodium-vapor dispersive Faraday filter in a lidar receiver, Opt. Lett., 21, 10931095, 1996.

Chen, S., Hu, Z., White, M. A., Chen, H., Krueger, D. A., and She, C.-Y.: Lidar observations of seasonal variation of diurnal mean temperature in the mesopause region over Fort Collins, Colorado (41 $\left.{ }^{\circ} \mathrm{N}, 105^{\circ} \mathrm{W}\right)$, J. Geophys. Res., 105, 12371-12379, 2000.

Chu, X., Pan, W., Papen, G. C., Gardner, C. S., and Gelbwachs, J. A.: Fe Boltzmann temperature lidar: design, error analysis, and initial results at the North and South Poles, Appl. Opt., 41, 44004410, 2002.

Eixmann, R., Gerding, M., Hoffner, J., and Kopp, M.: Lidars With Narrow FOV for Daylight Measurements, IEEE T. Geosci. Remote Sens., 53, 4548-4553, 2015.

Fleming, E. L., Chandra, S., Barnett, J. J., and Corney, M.: Zonal mean temperature, pressure, zonal wind, and geopotential height as functions of latitude, Adv. Space Res., 10, 11-59, 1990.

Fricke-Begemann, C. and Höffner, J.: Temperature tides and waves near the mesopause from lidar observations at two latitudes, J. Geophys. Res., 110, D19103, doi:10.1029/2005JD005770, 2005.

Fricke-Begemann, C., Alpers, M., and Höffner, J.: Daylight rejection with a new receiver for potassium resonance temperature lidars, Opt. Lett., 27, 1932-1934, 2002.

Friedman, J. S., Maldonado-Nieves, D., Gonzalez, I., Lautenbach, J., Chu, X., Smith, J. A., and Huang, W.: High spectral resolution test and calibration of an ultra-narrowband Faraday anomalous dispersion optical filter for use in daytime mesospheric resonance Doppler lidar, J. Atmos. Sol.-Terr. Phys., 80, 187-194, 2012.

Gerding, M., Höffner, J., Lautenbach, J., Rauthe, M., and Lübken, F.-J.: Seasonal variation of nocturnal temperatures between 1 and $105 \mathrm{~km}$ altitude at $54^{\circ} \mathrm{N}$ observed by lidar, Atmos. Chem. Phys., 8, 7465-7482, doi:10.5194/acp-8-7465-2008, 2008. 
Gerding, M., Höffner, J., Hoffmann, P., Kopp, M., and Lübken, F.J.: Noctilucent Cloud variability and mean parameters from 15 years of lidar observations at a mid-latitude site $\left(54^{\circ} \mathrm{N}, 12^{\circ} \mathrm{E}\right)$, J. Geophys. Res., 118, 317-328, 2013a.

Gerding, M., Kopp, M., Hoffmann, P., Höffner, J., and Lübken, F.J.: Diurnal variations of midlatitude NLC parameters observed by daylight-capable lidar and their relation to ambient parameters, Geophys. Res. Lett., 40, 6390-6394, 2013b.

Hauchecorne, A., Chanin, M. L., and Keckhut, P.: Climatology and trends of the middle atmospheric temperature $(33-87 \mathrm{~km})$ as seen by Rayleigh lidar over the south of France, J. Geophys. Res., 96, 15297-15309, 1991.

Klekociuk, A. R., Lambert, M. M., Vincent, R. A., and Dowdy, A. J.: First year of Rayleigh lidar measurements of middle atmosphere temperatures above Davis, Antarctica, Adv. Space Res., 32, 771-776, 2003.

Kopp, M., Gerding, M., Höffner, J., and Lübken, F.-J.: Tidal signatures in temperatures derived from daylight lidar soundings above Kühlungsborn $\left(54^{\circ} \mathrm{N}, 12^{\circ} \mathrm{E}\right)$, J. Atmos. Sol.-Terr. Phys., 127, 37-50, 2015.
Meriwether, J. W. and Gerrard, A. J.: Mesosphere inversion layers and stratosphere temperature enhancements, Rev. Geophys., 42, RG3003, doi:10.1029/2003RG000133, 2004.

Rauthe, M., Gerding, M., and Lübken, F.-J.: Seasonal changes in gravity wave activity measured by lidars at mid-latitudes, Atmos. Chem. Phys., 8, 6775-6787, doi:10.5194/acp-8-6775-2008, 2008.

von Zahn, U. and Höffner, J.: Mesopause temperature profiling by potassium lidar, Geophys. Res. Lett., 23, 141-144, 1996.

von Zahn, U., von Cossart, G., Fiedler, J., Fricke, K. H., Nelke, G., Baumgarten, G., Rees, D., Hauchecorne, A., and Adolfsen, K.: The ALOMAR Rayleigh/Mie/Raman lidar: objectives, configuration, and performance, Ann. Geophys., 18, 815-833, doi:10.1007/s00585-000-0815-2, 2000. 